\title{
Cardiovascular System Findings Consciousness State
}

National Cancer Institute

\section{Source}

National Cancer Institute. Cardiovascular System Findings Consciousness State. NCI

Thesaurus. Code C123942.

The level of awareness of an organism during a cardiovascular system assessment. 